\title{
Psychological and pedagogical approach to accompanying students with delayed speech development in the context of digitalization
}

\author{
Natalia Abashina ${ }^{1}$ and Natalia Berdnikova ${ }^{2}$ \\ ${ }^{1}$ Don State Technical University, 344003, Rostov-on-Don, Russia \\ ${ }^{2}$ Preschool educational No. 50, 344022, Rostov-on-Don, Russia
}

\begin{abstract}
The article discusses the psychological and pedagogical approach to accompanying young children with delayed speech development (delay in speech development manifests itself in a slower pace of mastering native speech by children under three years of age, underdevelopment of the vocabulary, lack of formation of expressive speech, lack of phrasal and coherent speech etc.). The purpose of the study is to develop a program of psychological and pedagogical support for young children with delayed speech development. During the testing of the program, special attention was paid to the processes of development of fine, general and articulatory motor skills of young children in various types of activity (play, cognitive, productive, communicative, etc.); the formation of mental processes (perception, thinking, memory, etc.); speech development of children (understanding of an adult's speech, development of auditory perception, correction of sound pronunciation, formation of a passive vocabulary, an increase in the volume of an active vocabulary, development of coherent speech, grammatical structure of speech, etc.); interaction of specialists and parents of young children (teacherpsychologist, speech therapist, teachers, educators, medical personnel, etc.) using offline and online technologies (consultations, workshops, seminars, open classes, etc.). As a result of approbation of the program in young children with delayed speech development, there were positive changes in the formation of speech and non-speech functions (understanding of the speech of others, the formation of a dialogue form of speech, the development of the motor sphere, etc.).
\end{abstract}

\section{Introduction}

One of the overriding priorities of modern education is the full and harmonious development of children at different stages of development, which requires a search for effective methods and techniques for achieving it. Early diagnosis and correction of anomalies in child development are becoming an urgent problem of special pedagogy, due to the fact that recently the number of children aged 2-3 years with disabilities in the development of the motor, speech and cognitive spheres has significantly increased, they write about this in their works. F.Arkhipova [1], O.G. Prikhodko [2], T.V. Surkova [3], O.V. Dobronravov, H.N. Galimova, A.V. Pankov [4] and others. 
In many studies, speech is considered as the most important psychological function (AN Leont'ev) [5]. Any violations in speech development are an object of study by specialists from different fields (defectology, special pedagogy and psychology, pediatrics, child psychiatry, etc.). Many scientists emphasize the fact that among the various forms of abnormal development of the psyche in early ontogenesis, speech disorders are the most common (M.L. Skuratovskaya, E.A. Klimkina, N.N. Abashina, N.A., Platokhina, etc.) [6; $7 ; 8 ; 9 ; 10]$.

In foreign studies, the problems of development and the provision of early assistance to children were considered by: G.W. McRoberts [11], D. E. Bernier, K.S. White [12], H. Chung, K. Farr, K. E. Pollock [13], E.I. Toki [14], T. Özdaş, A. SanemŞahlı, B. S. Özdemir, E. Belgin [15], P.J.Wang [16], S.R Zentall, B.J.Morris [17], D. P.Keating [18], J.E.V Lloyd, C.Hertzman [19], R. A. McDermott [20].

It becomes obvious that it is important for specialists working with children, parents to realize that disorders in speech development, as well as disorders in the development of mental processes in young children, can subsequently lead to severe speech and mental disorders, such as motor alalia, dysarthria, etc. Early detection of speech disorders, diagnosis and prevention of speech disorders contribute to the full speech development of children of early and junior preschool age, the formation of personality in general.

When considering the specific features of the delay in speech development, it becomes obvious that the delay in speech is reflected in a slower pace of mastering native speech by children under the age of three years of phrasal speech, as well as the lack of coherent speech in three-year-old children, etc.). Children who have a slow pace of speech development need a comprehensive examination of many specialists (speech therapist, teacher-psychologist, neurologist, otolaryngologist, as well as, if necessary, a medical diagnostic examination).

It becomes clear that work with children with delayed speech development should include two interrelated areas - psychological and pedagogical (as well as speech therapy) and medical (S.V. Vatoropina, E.N. Smorodina, S.V. Rakova, O.L Lekhanova, O.A Glukhova and others) $[21 ; 22]$.

One of the most effective forms of work with young children with delayed speech or mental development is psychological and pedagogical support. We consider psychological and pedagogical support as a special type of assistance to children, aimed at preventing possible speech and mental disorders in children of different ages. In the modern conditions of the development of society and education, the problem of organizing early assistance to children with speech disorders or speech underdevelopment remains relevant.

Early age is anauspicious period for the development of children's speech due to the plasticity and sensitivity of the child's psyche to various influences, provides great opportunities for optimizing psychological and pedagogical support. The purpose of early psychological and pedagogical support is to create optimal conditions necessary for the full physical and mental development, emotional and social well-being of the child.

The use of information technologies in the process of psychological and pedagogical support of children with special educational needs at different times was studied by: A.V. Bokov, B.P. Nevzorov, N.N. Zaguzin [23] and others. The authors use the following forms of behavior in their work with parents: consultations, conversations, trainings, surveys conducted both face-to-face and remotely (using tele- and videoconferencing, e-mail, stationary and mobile phone, etc.). Organization of the work of a telephone of trust for parents is also an effective form. At the same time, it is important that the parent is within the physical reach of the child, so that he needs help in time. 


\section{Materials and methods}

The urgency of the problem, an insufficient number of developed programs, technology has allowed us to formulate the purpose of research: to develop a program of psychopedagogical support for young children with delayed speech development.

The purpose of the program: creation of psychological, pedagogical, speech therapy conditions conducive to the effective development and correction of speech of young children.

In the course of solving the designated goal, special attention was paid to the following when working with young children with speech impairments:

- the development of fine, general and articulatory motor skills (in the process of play, cognitive, productive, communicative activities);

- the formation of mental processes (perception, thinking, memory, perception, etc.);

- the process of speech development of children (understanding the speech of an adult, developing auditory perception, correcting sound pronunciation, forming a passive dictionary, increasing the volume of an active dictionary, developing coherent speech, grammatical structure of speech, etc.);

- -interaction of specialists (teacher-psychologist, speech therapist, teachers, educators, medical personnel, etc.) and parents using offline and online technologies.

Table 1. The structure of the program of psychological and pedagogical support of young children with delayed speech development

\begin{tabular}{|c|c|}
\hline Sections of the program & Summary of program sections \\
\hline Target section & $\begin{array}{l}\text { Describe the goal, tasks of working with children with } \\
\text { speech disorders, psychological and pedagogical features of } \\
\text { the development of children of two to three years, the } \\
\text { planned results of mastering the program }\end{array}$ \\
\hline Content section & $\begin{array}{l}\text { Describes various types of activities with young children in } \\
\text { the following areas: speech therapy, psychological, general } \\
\text { education }\end{array}$ \\
\hline Organizational section & $\begin{array}{l}\text { Management of the process of development and correction } \\
\text { of speech in young children }\end{array}$ \\
\hline
\end{tabular}

The main tasks of the content section are: diagnostics of the formation of speech and non-speech functions in young children with delayed speech development, the development of skills in understanding the speech of others, stimulation of the children's need for verbal statements, the development of a passive and active vocabulary, the lexical and grammatical side of speech, the development of phonemic perception, the formation of a child's speech in conjunction with the development of higher mental functions (sensation, perception, attention, memory, thinking, imagination, emotional-volitional sphere), the development of the motor sphere, coordination of the efforts of specialists of a preschool educational institution, quality control of work with children. At the initial stage of work with children, problems related to adaptation to a pre-school educational institution were solved.

Particular attention was paid to the use of:

- game exercises with objects (for example, "Where is the doll?", "Train", "Rope", "Hen and chickens", "Bear", etc.);

- game exercises aimed at tactile contact with the child (for example, "Claws", "Swing", "Watch", "Airplane", "Our legs are walking on a flat path", "A bear in the forest", etc.);

- articulation exercises (for example, "Smile", "Wrinkle nose", "Good bunny", "Evil wolf", "Delicious jam", "Ball", etc.); 
- game actions with the ball (for example, "Catch the ball", "Roll the ball", "Throw in the basket", "Give the red ball", "Big-small ball", etc.);

- playing exercises for the development of fine motor skills (for example, "We sort out the groats", "Magic bag", "Beads", etc.).

During the course with children, the following methodological techniques were actively used: the method of commented actions, repeated repetition of speech forms, the use of a didactic puppet, solving elementary problem situations, transferring the knowledge gained to real life situations, a positive assessment of the child's actions.

The calendar-thematic plan for the implementation of the program presupposed conducting three lessons a week with the children, lasting up to 10 minutes.

During the implementation of the content section of the program, special attention was paid to the speech of adults - it was unhurried, expressive, emotional, without speech defects, simple and easy for children to understand. Throughout the work, teachers and parents accompanied all their actions with speech.

The organizational section of the program contains long-term plans for the work of teachers and specialists of a preschool educational organization with children and their parents, materials for the work of a teacher (card index of speech, musical, finger, breathing games for the development of correct breathing, motor skills, mental processes, etc.)

The interaction of the speech therapist with the parents of the pupils contributed to the solution of the following tasks: increasing the pedagogical competence of parents, encouraging parents to participate in the life of the group, harmonizing relations between children and parents, developing responsible parenting, skills of joint activities (speech, cognitive, play, communicative, productive, etc.).

To solve the above tasks, as part of the implementation of the organizational section of the program, we used offline and online technologies for interacting with the families of pupils:

- organization of offline and online questionnaires of parents on the topic "Speech development of an early age child: problems and solutions";

- conducting in an online format parent meeting, consultations on the following topics "Psychologist and pedagogical features of the development of young children", "What we have learned in a year", etc.;

- conducting offline consultations on the topics "Play methods for the development and correction of speech in young children", "When is it time to contact a speech therapist?", "Signs of delayed speech development", "The need for speech therapy assistance to non-speaking young children", "Creating speech environment at home". Traditional and nontraditional exercises for the development of fine motor skills in young children","Using the imitation method in the development of children's speech"," Using exercises to make words in the process of speech development in children"," Development of speech perception in children $2-3$ years"," Speech games for kids on the way from kindergarten home"," Development of speech based on familiarity with the world around";

- organization and conduct of online seminars-workshops for parents on the topic "The importance of fine motor skills development in the development of speech in preschool children", "Development of phonemic perception in children 2-3 years old";

- conducting joint offline classes with parents and children on the topics "My favorite toy", "Our magic fingers", "Colorful rings";

- organization of individual offline and online consultations at the request of parents. 


\section{Results}

As a result of the approbation of the program aimed at the development and correction of the speech of young children with delayed speech development, there were positive changes in the formation of speech and non-speech functions of babies, namely in understanding the speech of others, the formation of a dialogical form of speech, the development of auditory perception, sound pronunciation, passive vocabulary, an increase in the volume of the active vocabulary, the grammatical structure of speech, the development of fine, general and articulatory motor skills, in the development of higher mental functions. The children of the experimental group became calmer, sleep and appetite normalized, when meeting and parting with loved ones, the children showed a calm state, crying and crying were absent, impulsiveness and anxiety decreased. During the day, children cried less, sought contact with peers, were interested in toys, showed a desire to participate in various activities, adequately respond to the established rules of behavior, and strove to fulfill them. This proves that the work we have done is effective and yields significant results. Offline and online technologies of interaction of specialists with parents of children with speech disorders were recognized as effective.

\section{Discussion}

The study showed that the quality and effectiveness of the process of development and correction of the speech of young children increases under the condition of using a psychological and pedagogical approach to accompanying children with delayed speech development. Significant conditions for effectiveness are: taking into account the data of a diagnostic examination of speech and non-speech functions of children of two to three years old, taking into account the family situation in which a child with speech disorders is brought up, psychological and pedagogical competence of specialists, developing a subjectspatial environment, the use of correctional and developmental technologies in the process of development and correction of speech in young children.

\section{Findings}

We see prospects for the further development of the study in the development of an electronic diary of observation by parents of the speech development of children with delayed speech development, the development of a program for increasing the professional competence of specialists working with young children, the development of a model for providing early assistance to children with speech impairments attending and not attending a preschool educational institution.

\section{References}

1. E.F. Arkhipova, Logopedic work with young children (AST: Astrel, Moscow, 2007).

2. O.G. Prikhodko, Special education 4 (52), 95-105 (2018).

3. T.V. Surkova, TSU Science Vector 3 (17) 295-298 (2011).

4. O.V. Dobronravova, Kh.N. Galimova, A.V. Pankov, Baltiyskiy humanitarian journal 5. 4 (17), 271-273 (2016).

5. A.N. Leontiev, Psychological foundations of child development and learning (Smysl, Moscow, 2009). 
6. M.L. Skuratovskaya, E.A. Klimkina, Proceedings of the southern Federal University. Pedagogical Sciences 10, 119-125 (2016).

7. M. Skuratovskaya, E. Klimkina, Effectiveness of folk folklore as a means of early speech therapy, Innovative Technologies in Science and Education (ITSE-2020) 210.

8. M. Skuratovskaya, E. Klimkina, L. Kobrina, O. Fedotova, Overcoming barriers in communication of young children using the means of folklore of the peoples of the south of Russia, Proceedings of INTED2019 Conference 11th-13th March 2019, Valencia, Spain, 4566-4570.

9. N.A. Platokhina, I.V. Samarina, N.N. Abashina, Preventive Measures of Speech Disorders in Early Childhood, Procedia Social and Behavioral Sciences 233 (2016) 247-251. Annual International Scientific Conference Early Childhood Care and Education, ECCE 2016, 12-14 May 2016, Moscow, Russia.

10. N. Berdnikova, N. Abashina, E3S Web of Conferences 210, 18001 (2020). ITSE2020. https://doi.org/10.1051/e3sconf/202021018001

11. G.W. McRoberts, Encyclopedia of Infant and Early Childhood Development, 267-277 (2020)

doi: https://www.sciencedirect.com/science/article/pii/B978012809324523616Xvia\%3Dih ub.

12. D.E. Bernier, K.S. White, Journal of Experimental Child Psychology 185, 128-147 (2019).

13. H. Chung, K. Farr, K. E. Pollock, Journal of Communication Disorders 80, 18-34 (2019). doi: https://doi.org/10.1016/j.jcomdis.2019.03.003

14. E.I. Toki, J. Pange, Procedia - Social and Behavioral Sciences 2, 4274-4278 (2010). doi: https://www.sciencedirect.com/science/article/pii/S1877042810007184

15. T. Özdaş, A. Sanem Şahlı, B.S. Özdemir, E. Belgin, Brazilian Journal of Otorhinolaryngology 85, 199-205 (2019)

16. P.J. Wang, A.W. Hwang, H.F. Liao, P.C. Chen, W.S. Hsieh, Infant Behavior and Development 34 (3), 434-442 (2011).

17. S.R. Zentall, B.J. Morris, Journal of Experimental Child Psychology 107 (2) 155-163 (2010).

18. D.P. Keating, Early Education \& Development 18 (3) 561-570 (2017).

19. J.E.V. Lloyd, C. Hertzman, Social Science \& Medicine 68, 111-123 (2019).

20. R.A. McDermott, S.H. Rikoon, C. Waterman, J.W. Fantuzzo, School Psychology Review 41 (1), 66-81 (2012).

21. S.V. Vatoropina, E.N. Smorodina, S.V. Rakova, Scientific and methodological electronic journal «Concept» 5, 21-25 (2015).

22. O.L. Lekhanova, O.A. Glukhova, Nonverbal Encoding and Decoding of Nonverbal Communication Means as a Condition of Reflection Development in Communication in Children with Speech Underdevelopment 233, 504-507 (2016). doi: https://www.sciencedirect.com/science/article/pii/S1877042816314380

23. N.N. Zaguzin, B.P. Nevzorov, A.V. Bokov, Bulletin of the Kemerovo State University 2, 81-87 (2016). 